\title{
Sakha da(qany): Negative Polarity, Conjunction, and Focus
}

\author{
Ian L. Kirby*
}

\begin{abstract}
This paper discusses the quantifier particle da(qany) in the Siberian Turkic language Sakha (also known as "Yakut"). Focusing on its distribution in negative polarity items (NPIs) and doubled coordination constructions, it is shown that it has a distribution which is far more restricted than similar elements in other languages. In order to account for the semantics of this element, it is argued in an exhaustification-based theory of polarity sensitivity, that da(qany)'s main semantic contribution is to mark the alternative of its host as obligatorily active.
\end{abstract}

Keywords. Sakha language; Yakut language; coordination; disjunction; quantifier particles; negative polarity items (NPIs); focus; exhaustification; alternative semantics

1. Introduction. The Siberian Turkic language Sakha/Yakut (ISO sah) has a quantifier particle daqany $^{1}$ [dasani] , often phonologically reduced to $d a$ [da]. It appears in three main places: (1) in negative polarity items (NPIs), (2) in scalar focus environments, and (3) doubled in coordination structures.

Da(qany)-marked NPIs are built out of WH-words (1-a) and the numeral biir 'one' (1-b):

(1) Negative polarity items ${ }^{2}$
a. Min [tugu da(qany)] aax-*(pa)-t-ym
1SG [what.ACC da(qany)] read-(NEG)-PST-1SG
(Negative): 'I didn't read anything'
b. Min [biir da kinige-ni] aax-*(pa)-t-ym
$1 \mathrm{SG}$ [one $d a$ book-ACC] read-(NEG)-PST-1SG
(Negative): 'I didn't read any book' / 'I read no book'

In (1), da(qany) is grammatical in the negative versions of the sentences, but ungrammatical in the positive, a hallmark of NPIs. Building NPIs out of indefinite pronouns such as WH-word like tugu 'what' (1-a), or the numeral one (1-b), plus a particle like da(qany) ${ }^{3}$ is a common cross-linguistic strategy (Lahiri 1998; Chierchia 2013: 155-8), particularly when the particle elsewhere participates in scalar focus (i.e. 'even'), the second main uses of da(qany):

\footnotetext{
* I would like to thank Daria Boltokova for her tireless work in elucidating the meaning of this particle. I would also like to thank Jonathan Bobaljik, Uli Sauerland, and Dora Mihoc for guidance, as well as Vera Gribanova, Satoshi Tomioka, Jim Huang, Andreea Nicolae, Gennaro Chierchia, Hande Sevgi, Deniz Satık, Gunnar Lund, Tamisha L. Tan, Niels Torben Kühlert, Aurore Gonzalez, Tamás Halm, the audience at the Tu+5 Workshop, and the reviewers. Author: Ian Kirby, Harvard University (ikirby@g.harvard.edu)

${ }^{1}$ I adopt Vinokurova's (2005) Romanization of Cyrillic <дақаны $>$, where $q=[\mathrm{\gamma}] \sim[\mathrm{s}]$ and $\mathrm{y}=[\mathrm{i}] \sim[\mathrm{u}]$. Other letters reflect their IPA vowels, with the exception of the following: $d j=[\jmath], \ddot{o}=[\varnothing], \ddot{u}=[y]$. Long vowels phonemes are represented as doubles (e.g. $\mathrm{aa}=[\mathrm{a}] \mathrm{c})$, consistent with the orthography. $/ \mathrm{x} /$ has an syllable-initial allophone $\left[\mathrm{q}^{\mathrm{h}}\right]$ (e.g. xanna $\left[\mathrm{q}^{\mathrm{h}}\right.$ anna] 'where'.)

2 The glosses follow Leipzig Glossing Rule conventions, except for CMPR=comparative case, REMPST=remote past.

${ }^{3}$ Following determiners shorter than three syllables (e.g. biir 'one' (1-b)), reduced da is preferred.
} 
(2) Scalar focus

a. [Onnooqor stud ${ }^{j}$ en da(qany)] iti kinige-ni aax-(pa)-ta

[even student da(qany)] that book-ACC read-(NEG)-PST.3SG

'Even the student (didn't) read that book'

b. [Elbex da kihi] kinige aax-(pa)-ta

[many $d a$ person] book read-(NEG)-PST.3SG

(Positive): 'So many people read the book'

(Negative): 'So few people read the book'

In (2), da(qany) marks an element that is contextually unexpected-that is, (2-a) is only felicitious if the speaker considers it comparatively unlikely that the student would read the book (or that the student would not read it, in the case of negation). Unlike its use with WH-words and biir (1), the positive versions of these sentences are grammatical.

The third main use of $d a(q a n y)$ is when it is doubled, where it results in a coordination:

(3) Da(qany)...da(qany) coordination

a. Djulus [kof ${ }^{\mathrm{j}} \mathrm{e}$ da(qany)] [caj da(qany)] is-pe-te

Djulus [coffee da(qany)] [tea da(qany)] drink-NEG-PST.3SG

'Djulus drank neither coffee nor tea'

$\neg($ coffee $\vee$ tea $)$

b. Djulus [kof ${ }^{j} \mathrm{e}$ da(qany)] [caj da(qany)] is-te

Djulus [coffee $d a($ qany)] [tea $d a($ qany)] drink-PST.3SG

'Djulus drank both coffee and tea'

$($ coffee $\wedge$ tea $)$

In (3), we see two key properties of $d a$ (qany) coordination. Firstly, da(qany) appears to the right of both coordinands. Parallel sentences with only a single instance of da(qany) are ungrammatical. ${ }^{4}$ Secondly, we see that both negative (3-a) and positive (3-b) examples are grammatical, but the interpretation is different. Negation results in a 'neither...nor' meaning (3-a), while positive sentences receive a 'both... and' reading (3-b).

The distribution da(qany) is theoretically important for many reasons. Da(qany)'s distribution is similar, but not identical to particles in other languages. When an element in a language is highly restricted to particular semantic environments, the immediate question we are confronted with is what logical property allows the element to be grammatical in those environments to the exclusions of other. This question become even more intriguing when we look at the cross-linguistic patterns of such particles. Elements discussed in the literature that appear in both NPIs and 'both...and' coordination typically have properties that da(qany) lacks, the most immediate being use as an additive particle, as exemplified by the Hungarian particle $i$ :

(4) Hungarian is

a. Vala-ki is some-who is 'anyone' (NPI) (Szabolcsi 2018, (22))

b. [Kati is] (alszik), [Mari is] (alszik), [Peti is] alszik [Kati is] (sleeps), [Mary is] (sleeps), [Peti is] sleeps 'Kati, Mari, and Peti are sleeping' (Szabolcsi 2018, (44-b))

\footnotetext{
${ }^{4}$ One caveat is a (potentially) similar concessive construction $[X$ da (qany) $Y]$ 'even though $\mathrm{X}, \mathrm{Y}$ ' (see §2.1.2).
} 
c. Mari fészekelődött. [BILL is ásított]

Mary was.fidgeting. [BILL is yawned]

'Mary was fidgeting. BILL yawned, too' (Szabolcsi 2017, (5))

The is-pattern (4) is shared by Bosnian/Croatian/Serbian (BCS) $i$ (Szabolcsi 2017), as well as Japanese -mo (ibid.). ${ }^{5}$ In (4-c), with focus on 'Bill' (signified by caps) in combination with is signifies somebody other than Bill yawned (in addition to Bill). Crucially, Sakha da(qany) is ungrammatical in additive focus environments:

Djulus kof $\mathrm{j}_{\mathrm{e}}$ is-te. $\quad\left[\mathrm{Min}\left\{{ }^{*} \mathrm{da}(\mathrm{qany}) / \mathrm{emie}\right\}\right.$ is-t-im]

Djulus coffee drink-PST.3SG. [1SG \{da(qany) / emie $\}$ drink-PST-1SG]

'Djulus drank coffee. I drank (coffee), too.'

Examples like (5) with da(qany), where the desired reading is intended to be analogous to (4-c), are ungrammatical. Instead, another particle emie is used for these roles. Of the quantifier particles in other languages I have examined, $d a$ (qany) is unique in lacking this reading.

What is at stake theoretically is what the exact semantic contribution of a particle which is at home in these two prima facie quite disparate environments could be, and how it allows these readings to come about. One standard view holds NPIs to be existentials which obligatorily scope below negation (Fauconnier 1975, Ladusaw 1979, Chierchia 2013, Crnič 2014). Existentially quantified propositions $(\exists \mathrm{x}[\mathrm{A}(\mathrm{x}) \wedge \mathrm{B}(\mathrm{x})])$ are logically equivalent to proposition-level disjunction ( $\mathrm{p} \vee \mathrm{q}$ ), while universally quantified propositions $\forall \mathrm{x}[\mathrm{A}(\mathrm{x}) \rightarrow \mathrm{B}(\mathrm{x})]$ are eqiuvalent to proposition-level conjunction $(\mathrm{p} \wedge \mathrm{q})$. If we assume that da(qany)-marked phrases are existentials/disjunction at their core, how can we account for the conjunctive 'both...and' meaning of $d a($ qany)...da(qany) in sentences like (3-b)?

This paper provides a semantic proposal for da(qany)'s use in Sakha NPIs (1) and coordination (3). Adopting the alternative-semantics based Grammatical Theory of Polarity Sensitivity (Chierchia 2013), it is argued that da(qany) marks the grammatical alternatives of its host as obligatorily active. These alternatives are in-turn interpreted by a covert exhaustifier. This accounts straightforwardly for its NPI behavior, because in positive environments exhaustification will result in contradiction.

To account for the 'both....and' reading in sentences like (3-b), I propose that da(qany)... da (qany) is underlying a disjunctive or $(\mathrm{p} \vee \mathrm{q})$ meaning which is uniformly strengthened to conjunction $(p \wedge q)$ in positive environments via recursive exhaustification of the domain alternatives $\{p, q\}$ without exhaustifying any stronger scalar alternative $(p \wedge q)$. This has been proposed for a variety of elements which display an existential/disjunction reading under negation, but are universal/conjunction in positive environments (see Szabolcsi 2017 for review.)

The structure of this paper is as follows. \$2 discusses the distributional facts within Sakha, restricting the discussion to NPIs and coordination. $\$ 2$ also discusses cross-linguistic comparison of similar particles in other languages. \$3 gives a semantic account of da(qany).

2. Distribution and Cross-linguistic Typology. Da(qany) displays an incredibly restricted distribution. To explain the meaning of such an element, we must both describe the relevant aspects of its occurrence (\$2.1) and also compare this distribution to that of similar elements in

5 Japanese - $m o$ also functions as a universal quantifier, a role which da(qany) also lacks (discussed in $§ 2.2, \S 3.3$ ). 
other languages (\$2.2). ${ }^{6}$ In $\$ 2.2$, da(qany)'s distribution is compared to the Hungarian particle is/sem (Szabolcsi 2017), the Bosnian/Serbian/Croatian (BCS) particle $i / n i$ (ibid.), the Japanese particle -mo (Kratzer \& Shimoyama 2002, Shimoyama 2006, Szabolcsi 2015), and the Hebrew quantifier kol (Bar-Lev \& Margulis 2014). ${ }^{7}$ While there is nontrivial overlap between these elements and da(qany), Sakha is distinct in two key aspects: (I) da(qany) lacks additive too/either readings (contrasting with all but Hebrew kol); (II) da(qany) does not appear in universal quantifiers or universal free-choice items (unlike Hebrew kol, Japanese -mo).

2.1. Distribution OF DA(QANY). This subsection discusses the distribution and licensing of da(qany)-marked NPIs (\$2.1.1), da(qany)...da(qany) coordination (\$2.1.2), and the alternation between full daqany and reduced $d a(\S 2.1 .3)$.

2.1.1. NPIs. Sakha da(qany)-marked NPIs come in two forms: WH+da(qany) and biir da+N NPIs. These are licensed by a variety of semantically negative morphemes, such as the negative suffix $-B A$ (see above), the negative copula suox (6-a), the prohibitive suffix -Ima, the negative converb -BAkka (6-c), and the auxiliary ilik 'not yet' (6-d).
a. [[Tuox da(qany)] syala $\quad\{$ suox $\quad / *$ baar $\}]$ suruj-but-um [[what da(qany)] purpose \{NEG.COP / COP $\}]$ write-REMPST-1SG
'I wrote for no reason'
b. $\quad\{$ Tugu da(qany) / biir da kinige $\}$ aaq-*(yma)
\{what.ACC $d a$ (qany) / one $d a$ book $\}$ read-(NEG.IMP)
'Don't read anything' / 'Don't read any book'
c. \{Tugu da(qany) / biir da kinige $\}$ aax-pakka ereeri üören-n-im \{what.ACC $d a($ qany) / one $d a$ book\} read-NEG.CVB even.though study-PST-1SG 'I studied without reading anything/any book'
d. [[Kim da(qany)] [biir da kinige] aax-a] ilik [[who $d a($ qany)] [one $d a$ book] read-CVB] not_yet.3SG 'Nobody has read any book(s) yet'

Aside from negation, da(qany) NPIs are also grammatical in comparatives. Sakha comparatives are formed with a case suffix $-T \bar{A} q A r$ (Stachowski \& Menz 1998: 429) as in (7-a).

a. Tujara Djulus-taaqar uhun

Tujara Djulus-CMPR tall

'Tujara is taller than Djulus'

b. Tujara [kim-neeqer da(qany)] uhun

Tujara [who-CMPR da(qany)] tall

'Tujara is taller than anyone'

Unlike NPIs in many languages (e.g. English ever, any), da(qany) is not licensed in the antecedent of a conditional (8), nor in polar questions (9). Rather, there are other quantifer particles ere and emielemit which serve this role (Haspelmath 1997).

\footnotetext{
${ }^{6}$ Because the main aim of this paper is to account for da(qany)'s role in NPIs and 'both...and'/'neither...nor' coordination, da(qany)'s use in scalar focus constructions like (2) is set aside.

${ }^{7}$ I have chosen not to discuss $d a$ (qany)'s cognates in other more well-studied Turkic languages (e.g. Turkish), because they generally do not appear in NPIs outside of the Siberian branch of Turkic (see Kirby 2020 for discussion).
} 
[Tujara [tugu $\quad\{*$ da(qany) / emit $\}]$ onor-doquna] Djulus caj kut-an

[Tujara [what.ACC $\{d a($ qany) / emit $\}]$ repair-COND.3SG] D. tea pour-CVB

bjer-iexteex

serve-FUT.3SG

'If Tujara repairs anything, Djulus will serve tea'

(9) $[\operatorname{Kim}\{*$ da(qany) / emit / ere $\}]$ kofje ih-er=yj

[who $\{$ da(qany) / emit / ere $\}]$ kofje drink-AOR.3SG=Q

(kim emit): 'Does anyone drink coffee'

(kim ere): 'Does someone (in particular) drink coffee?'

While discussion of the particulars of why da(qany)-NPIs are ungrammatical in conditionals (8) and questions (9) is outside the scope of this paper, it should be noted that the small class of licensers of da(qany) NPIs does not pose a significant. Negation and clausal comparatives form a semantic class of Anti-Additive functions (Hoeksema 1983, Zwarts 1996) and licensing via negation and comparatives is observed in many languages (see Haspelmath 1997: 68-75).

2.1.2. CoOrdination. Aside from the 'neither...nor'/'both...and' flip with respect to negation, da(qany)...da(qany) coordination displays many interesting properties. Phrases of any syntactic label can be coordinated, including NPs (3), VPs (10-a), and adjectives (10-b).
a. Min iti kinige-ni [aaq-a da(qany)] [suruj-a da(qany)] ilik-bin
1SG that book-ACC [read-CVB da(qany)] [write-CVB da(qany)] not_yet-1SG 'I neither read nor wrote that book'
b. Min [kyhyl da(qany)] [küöx da(qany)] kinige-ni aax-(pa)-t-ym
1SG [red da(qany)] [green/blue da(qany)] book-ACC read-(NEG)-PST-1SG
(Pos): 'I read the red and the blue book' / (Neg): 'I read neither the red nor the blue book'

Da(qany)...da(qany) can also coordinate full clauses:

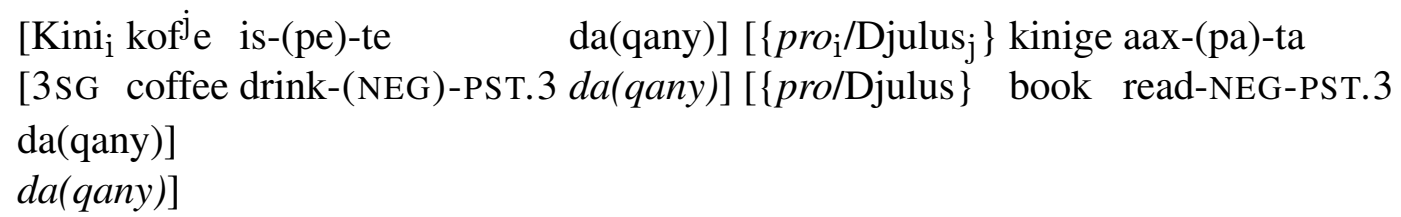

(Pos): 'He drank coffee and he/Djulus read a book' / (Neg): 'He neither drank coffee nor did he/Djulus read a book' 8

As indicated by the grammaticality of Djulus in (11), the subject of both the left and right clauses are not required to be identical. If only the co-indexed, pro-dropped reading of the right clauses were allowed, this would best be analyzed as coordinated VPs. ${ }^{9}$

So far, all of the examples of $d a($ qany)...da(qany) coordination have been structurally parallel, but this is not a requirement: da(qany) can mark phrases embedded inside coordinands. This is particularly salient when coordinating objects of different lexical verbs (12):

\footnotetext{
${ }^{8}$ Note for the the 'neither...nor' reading of (11), the negative suffix - $B A$ is required is required on both verbs. While it is likely that structurally $d a$ (qany) is outside the scope of negation (and thus a better paraphrase would be 'He both didn’t drink coffee and didn’t read a book'), the semantic proposal in $\$ 3.2$ is consistent with either scope.

${ }^{9}$ For the purposes of this paper, I make no commitments about whether da(qany)...da(qany) coordination is always coordination of CPs with ellipsis of repeated material, or if it can involve coordination of smaller elements.
} 
$\left[\right.$ Kini $_{\mathrm{i}}\left[\mathrm{kof}^{\mathrm{j}} \mathrm{e}\right.$ da(qany) $]$ is-(pe)-te $] \quad\left[\left\{\right.\right.$ pro $_{\mathrm{i}} /$ Djulus $\left._{\mathrm{j}}\right\}$ [kinige da(qany)]

[3SG coffee da(qany) drink-NEG-3SG] [\{pro / Djulus $\}$ book da(qany)

aax-(pa)-ta]

read-NEG-PST.3SG]

(Pos): 'He drank coffee and he/Djulus read a book' / (Neg): 'He neither drank coffee, nor did he/Djulus read a book'

Comparing (12) (where da(qany) appears right of the objects) to (11) (where da(qany) appears right of the clauses), there is a semantic/pragmatic distinction which is particularly salient in the positive version. When da(qany) appears to the right of clauses (11), there is a contextual expectation that only one of these two propositions (him drinking coffee, him/Djulus reading a book) is likely to obtain. For example, if we have background knowledge that the subject of (11) is limited on time and would likely have to choose between drinking coffee and reading a book, this placement of $d a$ (qany) would be felictious. On the other hand, when da(qany) appears to the right of objects of a verb (12), it is not the predicates that are unexpected, but rather the objects themselves. In other words, there is an expectation that the subject of (12) would read drink something other than coffee and/or read something other than a book.

This sensitivity to context is something that distinguishes da(qany)...da(qany) in positive sentences from negative ones. Expectations of this sort are always required for positive $d a($ qany)...da(qany). Out of the blue, positive $d a(q a n y) . . . d a(q a n y)$ is pragmatically odd. Negative $d a($ qany)...da(qany) does not display contextual sensitivity. This is expected from an analysis where da(qany) is an operator which activates semantic alternatives, as argued in $\S 3$.

Finally, as was mentioned in $\S 1$, da(qany)...da(qany) coordination always involves da(qany) marking each coordinand, though in footnote 4 , I mentioned a caveat about a potentially similar construction which results in a concessive reading:

[Djulus öjdööx da(qany)] [onno bar-byt]

[Djulus clever da(qany)] [there go-REMPST.3SG]

'Even though Djulus is smart, he went there' / 'Djulus is smart, but he went there'

While (13) looks very much like da(qany)...da(qany) coordination of clauses (11) minus the da(qany) on the right coordinand, there are notable differences. Da(qany)...da(qany) coordination requires that the phrases da(qany) appears to the right of have the same syntactic label (i.e. mismatches are ungrammatical. see Vinokurova 2005: 202): ${ }^{10}$. Compare (14) to (13).
*Djulus öjdööx da(qany) onno bar-byt
da(qany)
Djulus clever da(qany) there go-REMPST.3SG da(qany)
Intended: 'Djulus is smart and (he) went there'

Sentence (14) is ungrammatical because the left da(qany) appears next to a predicative adjective, while the right occurs next to a finite verb. The concessive use of da(qany) (13) is more akin the the scalar focus reading of the particle (2). Because I will not be discussing this use of the particle, I will not discuss the concessive meaning further, though ultimately these facts can also be accounted for within the approach outlined in this paper (see Kirby 2020).

\footnotetext{
${ }^{10}$ Further, comparing (11) and (12) again, da(qany) cannot be embedded in one coordinand and outside the other (i.e. *[...kofje da(qany) is(pe)te][...kinige aax(pa)ta da(qany)], etc.)
} 
2.1.3. Alternation Between full DaqAny AND Reduced DA. Some comments on the alternation between full daqany and reduced $d a$ are in order. This alternation was noted in the earliest description of Sakha (Böhtlingk 1964 [1851]), though I am unaware of any descriptions which discuss what governs the alternation. From examples I have observed, there are three general tendencies: firstly, wherever full daqany is acceptable, $d a$ is also acceptable (but not vice versa); secondly, when da(qany) appears as the final element of the phrase it modifies, both forms are acceptable (15); thirdly, when da(qany) appears in the second position in the phrase it modifies, reduced $d a$ is preferred if the word to the left is two syllables or fewer (16).

Da(qany) final element in phrase.
a. [tugu da(qany)]
'anything' (NPI, (1-a))
b. [kim da(qany)]
[who da(qany)]
'anybody' (NPI)
c. [onnooqor studjen da(qany)]
[even student da(qany)]
'even the student' (Scalar focus,
$(2-a))$

(16)

Da(qany) second position in phrase:
a. [biir da(?? qany) kinige-ni]
[one da(qany) book-ACC]
'any book' (NPI, (1-b))
b. [elbex da(?? qany) kihi]
[many da(qany) person]
'so many/few people' (scalar fo-
cus, (2-b))
c. [aqyjax da(qany) oqo-loox-tor]
[few da(qany) child-HAVE-PL]
'Even those with few children'
(scalar focus)

So far, very few examples have been identified where the alternation results in a detectable difference in meaning in and of itself. The alternation thus seems to be largely phonological. One important fact that this reveals is that full daqany and reduced $d a$ are the same lexical item and hence likely have the same semantic contribution in all contexts, as the same constraints in reduction are present in each role. Because da(qany) appears as the final element of each coordinand in a $d a($ qany)...da(qany) coordination, both options are available, similar to (15).

2.2. CROss-Lingusitic Typology. There is a growing literature on the cross-linguistic typology quantifier particles and their hosts, which seeks to explain the semantics of the particle as stable across the environments they occur in (Szabolcsi 2010, 2015, 2017, 2018). Following from this general approach, the task is to determine what semantic operations, coupled with a denotation of da(qany), could lead these two prima facie disparate interpretations (i.e. NPIs and 'both....and' coordination).

The distribution of Sakha da(qany) so far is pulling us in two directions. On the one hand, the fact that it appears in NPIs suggests that it is existential/disjunction, an analysis which jibes well with the 'neither...nor' reading of da(qany)...da(qany) under negation. On the other hand, if it is essentially disjunction, how can we account for the 'both...and' reading of da(qany) ...da(qany) coordination in positive environments? Further, from comparing the phonological tendencies for where daqany is reduced to $d a$ (\$2.1.3), it seems likely that da(qany) in all of these environments is the same lexical item and hence has the same definition.

One way to consider this is that we are dealing with two different, but related, types of quantification: $\mathrm{WH}+d a(q a n y)$ and biir $d a+\mathrm{N}$ NPIs are functions over sets of individuals (i.e. type $\langle$ et, $\mathrm{t}\rangle$ ), while $d a($ qany)...da(qany) coordination is a function over sets of propositions (i.e. $\langle\mathrm{tt}, \mathrm{t}\rangle)$. Da(qany) modifies a function which has the force of an existential quantifier in NPIs 
and propositional disjunction in the 'neither...nor' versions of da(qany)... da(qany). Because existentials are logically equivalent to disjunction, these two uses are expected. On the other hand, we only ever see $d a(q a n y)$ with a universal/conjunction reading in positive da(qany)...da(qany) coordination-if it were able to contribute universal conjunction to sets of type $\langle$ et, $t\rangle$, we would anticipate that the positive version of a sentence like (17) would be interpreted as 'Everybody read that book' rather than simply being ungrammatical.

[Kim da(qany)] iti kinige-ni aax-*(pa)-ta

[who da(qany)] that book-ACC read-(NEG)-PST.3SG

'Nobody read that book'

To compare the typological situation of the distribution of da(qany), it is pertinent to compare its roles to particles in other languages which appear in NPIs as well as conjunction/universal quantification. Because they are well-studied and have played crucial roles in theoretical discussion of quantifier particles (see references below), I have chosen to draw parallels to the Hungarian particle is/sem (discussed in $\S 1$, example (4)), BCS $i / n i$, the Hebrew $k o l$, and Japanese $-m o{ }^{11}$ The relevant uses are shown in Table 1:

\begin{tabular}{|c|c|c|c|c|c|}
\hline Role & Sah da(qany) & Hun $i s /$ sem & $\mathrm{BCS} i / n i$ & Heb kol & Jpn -mo \\
\hline everyone, $\forall$ & $x$ & $\bar{x}$ & $\bar{x}$ & kul-am & daré-mo \\
\hline anyone, FCI & $x$ & akár-ki is & $x$ & kol-exad & dare-de-mo \\
\hline anyone, NPI & kim da(qany) & $\begin{array}{l}\text { vala-ki is, } \\
\text { akár-ki is }\end{array}$ & i-(t)ko & kol-exad & dare-mo \\
\hline both $\mathrm{X}$ and $\mathrm{Y}$ & $\begin{array}{c}\text { X da(qany)... } \\
\text { Y da(qany) }\end{array}$ & $\mathrm{X}$ is $\mathrm{Y}$ is & i X i Y & $\bar{x}$ & X-mo Y-mo \\
\hline neither $\mathrm{X}$ nor $\mathrm{Y}$ & $\begin{array}{c}\text { X da(qany)... } \\
\text { Y da(qany) }\end{array}$ & $\begin{array}{l}\text { sem } X \text { sem } Y, \\
X \text { sem } Y \text { sem }\end{array}$ & ni $X$ ni $Y$ & $x$ & X-mo Y-mo \\
\hline X too & $x$ & $\mathrm{X}$ is & i X & $x$ & X-mo \\
\hline even $\mathrm{X}$ & $\begin{array}{c}\text { onnooqor X } \\
\text { da(qany) }\end{array}$ & még $X$ is & čak i X & $x$ & X-mo \\
\hline
\end{tabular}

Table 1. The main semantic roles of quantifier particles in Sakha compared to Hungarian (Szabolcsi, see citations above), Bosnian/Croatian/Serbian (Szabolcsi 2017, Progovac 1994), Modern Hebrew (Bar-Lev \& Margulis 2014, Glinert 1989), and Japanese (Szabolcsi 2015, Shimoyama 2006, 2011). $\forall=$ universal quantifier, FCI = free chioce item.

Considering the left-most cells of Table 1, from top to bottom the roles are grouped into three semantic classes (indicated by double line breaks): the first three (everyone $(\forall)$, anyone (FCI), and anyone (NPI)) are quantification over sets of individuals $\langle$ et, $\mathrm{t}\rangle$; the next two (both $\mathrm{X}$ and $\mathrm{Y}$, neither $\mathrm{X}$ nor $\mathrm{Y}$ ) are quantification over sets of propositions $\langle\mathrm{tt}, \mathrm{t}\rangle$; the bottom two (X too,

11 As indicated in fn 7, I do not include the da(qany)'s in other Turkic languages because they generally do not form NPIs. In Turkish for example, $d A$ can associate with additive (X too) or scalar (even X) focus Szabolcsi (2018), and can mark 'both...and' coordination (Kornfilt 1997: 109-10) (interpreted as neither...nor with negation). It can, however, mark scalar focus on NPIs (e.g. kimse 'anybody'), universal quantifiers (e.g. herkes) 'everyone', and FCIs (e.g. herhangi bir 'anywhich one'), but unlike the particles in Table 1, these words serve those roles irrespective of $d A$. 
even $\mathrm{X}$ ) are focus environments. We see that Japanese -mo is a highly flexible particle, appearing in all of the relevant roles with variable quantificational force. While Hebrew kol only appears in functions of type $\langle$ et, $\mathrm{t}\rangle$, the quantificational force is varied. Hungarian is/sem and BCS $i / n i$ largely overlap, ${ }^{12}$ differing only in that Hungarian is appears in the NPI/FCI akárki $i s$, while BCS $i$ lacks FCI uses.

Two main generalizations emerge from Table 1. First, we see that there is an overlap between the availability of these elements to occur as scalar particles (i.e. even X), the presence of the particles in NPIs, and their presence in 'both...and' and 'neither...nor' constructions. In this set, we see that Sakha is distinct in lacking the an additive (i.e. $\mathrm{X}$ too) reading (discussed in $\$ 1,(5))$. Additive too is a presupposition that some other proposition other than the focus value of too is true. While additivity would be a convenient avenue to explay why Hungarian $i s / s e m$, BCS $i / n i$, and Japanese -mo appear in both conjunction 'both X and Y' (a link proposed in Szabolcsi (2017)), the fact that da(qany) participates in these constructions, but not too focus suggests that it is not strictly required.

The second generalization emerging from Table 1 is that da(qany) lacks uses in free-choice items (similar to BCS $i / n i) .{ }^{13}$ As will be shown in $\$ 3$, this fact is at tension with my analysis of $d a($ qany)...da(qany) coordination, a tension that I resolve in $\S 3.3$.

3. Semantic proposal for da(qany). Before diving into the proposal for Sakha da(qany)'s semantics, some general remarks about the Grammatical Theory of Polarity Sensitivity (Chierchia 2013) are in order. Drawing on the long-noted observation that there is an inverse relationship between the availability of scalar implicatures and the licensing of NPIs (Chierchia et al. 2008), this theory holds that the crucial semantic ingredient involved in NPI-hood is the presence of grammaticalized alternatives. Because these alternatives are part of the lexical denotation of NPIs, they are obligatory. Starting from the basic assumption that NPIs are existentials/disjunctions at their semantic core, this theory relies on the notion of exhaustification to explain why these words are grammatical in negative sentences, but ungrammatical in positive ones. An exhaustifier is a covert operator which performs some pre-defined operations on the alternatives of the scalar element. The most basic exhaustifier is $\mathrm{O},{ }^{14}$ a covert counterpart to only (Rooth 1985, Chierchia et al. 2008, Chierchia 2013).

$\mathrm{O}_{\mathrm{ALT}}(\phi)=\phi \wedge \forall \psi \in \mathrm{ALT}[\psi \rightarrow \phi \subseteq \psi]$, where ' $\subseteq$ ' means 'entails' (Chierchia 2013) i.e. $\mathrm{O}(\phi)$ asserts $\phi$ and eliminates (i.e. negates) all the alternatives not entailed by $\phi$.

To paraphrase the definition of $\mathrm{O}(\mathrm{nly})$ (18) in plain language, its purpose is to take a proposition (known as the "prejacent") which has alternatives, and to assert that prejacent while negat-

\footnotetext{
12 The difference between Hungarian is, BCS $i$ on the one hand and sem, ni on the other is that the latter display negative concord (reflected in the 'neither X nor Y' roles for these languages). Valaki is and $i$ - $(t) k o$ are weak NPIs, meaning they are not licensed in the direct scope of clause-mate negation (but are licensed in indirect negation, e.g. I don't think[he read anything]). With clause-mate negation, the forms are sen-ki (=sem-who) and ni-(t)ko, respectively. While da(qany) does not display traits of negative concord (e.g. da(qany) NPIs cannot serve as negative fragment answers to non-negative question), even if it did, it would not pose a significant hurdle, following the assumption that negative concord items are NPIs with a negative piece added (see Chierchia 2013: ch. 4)

${ }^{13}$ A type of free choice implicature can be detected when the scalar use (onnooqor) X da(qany) appears in the scope of a possibility modal. Because it is derived from an interaction with the scalar implicature and is not inherent to any host+da(qany) constructions, I do not analyze this as a true free-choice item (see Kirby 2020)

${ }^{14}$ Note that the O-exhaustifier follows Chierchia's (2013) convention. It is largely equivalent to exh used in much other work in this framework (e.g. Fox 2007, Chierchia et al. 2008).
} 
ing its non-entailed alternatives. Following from the theoretical assumption that NPIs have grammatically defined alternatives which cannot be pruned by pragmatic relevance (i.e. they are obligatory, unlike ordinary scalars), this has the result of producing contradictions when NPIs appear in positive environments. It is this contradiction which is the source of ungrammaticality of NPIs in positive sentences.

In what follows, I will extend this theory to $d a$ (qany), proposing that da(qany) itself has the function of marking the alternatives of its host as obligatorily active, following an idea from Szabolcsi (2017: 461) that activating alternatives can be delegated to a single morpheme (§3.1). This is an addition to Chierchia’s (2013) system, which holds that it is a lexical property of NPIs like English any that they have obligatory alternatives as part of their definition. In other words, for the Sakha data, da(qany)'s host has alternatives independently, but da(qany) makes them obligatory.

To account for the 'both...and' reading (\$3.2), I start with the assumption that da(qany) ...da(qany) is at its core a semantic disjunction (i.e. or). To systematically produce conjunctive 'both...and' meanings, I propose that it is exhaustified recursively with O(nly) without exhaustifying a stronger scalar alternative. In $\S 3.3$, I briefly show that this is at tension with the account of NPIs, a tension I resolve by proposing that the fact that da(qany) appears multiple times in coordination constructions signifies that exhaustification need be applied recursively. ${ }^{15}$

3.1. DA(QANY) NPIS. With the basics of the framework in place, we can now give a semantic account of $d a$ (qany) NPIs. Here, I will only be considering $\mathrm{WH}+$ da(qany) NPIs. ${ }^{16}$

$$
\begin{aligned}
& \text { Min [kimi da(qany)] kör-*(bö)-t-üm } \\
& 1 \mathrm{SG} \text { [who.ACC da(qany)] see-(NEG)-PST-1SG } \\
& \text { 'I didn't see anybody' }
\end{aligned}
$$

The starting point for a denotation of (19) is the definition of kim 'who'. As a WH-indefinite, $\mathrm{kim}$ is an existential quantifier with an argument that is already saturated (Dayal 2016):

$$
\llbracket k i m \rrbracket=\llbracket \text { who } \rrbracket=\llbracket \text { someone } \rrbracket=\lambda \mathrm{P}_{\langle\mathrm{e}, \mathrm{t}\rangle} \cdot \exists \mathrm{x} \in \mathrm{D}_{\mathrm{e}}[\operatorname{person}(\mathrm{x}) \wedge \mathrm{P}(\mathrm{x})]
$$

If kim da(qany) were not an NPI, the meaning of the positive counterpart of (19) would be a basic existential like in (21).

$$
\llbracket \text { I saw someone } \rrbracket=\exists x \in D_{e}[\operatorname{person}(\mathrm{x}) \wedge \operatorname{saw}(\mathrm{I}, \mathrm{x})]
$$

Next, we need to spell out the alternatives of an LF like (21). Considering a domain with two members \{Djulus, Tujara\}, (21) is equivalent to a disjunction of two propositions $(p \vee q)$, were $\mathrm{p}=$ 'I saw Djulus' and q='I saw Tujara'. These two propositions $\{\mathrm{p}, \mathrm{q}\}$ are members of the alternative set $(p \vee q)$ known as subdomain alternatives (Sauerland 2004). In addition, ( $p \vee q)$ has a stronger scalar alternative $(p \wedge q)$. This set of alternatives can be represented in a semi-lattice:

$$
\begin{aligned}
& \text { Alternatives of }(\mathrm{p} \vee \mathrm{q}) \\
& \begin{array}{|ccc|l}
\hline \multicolumn{3}{|c|}{(\mathrm{p} \vee \mathrm{q})} \\
\mathrm{p} & & \mathrm{q} & \begin{array}{l}
\text { (prejacent) } \\
(\text { subdomain alternatives }) \\
\end{array} \\
& (\mathrm{p} \wedge \mathrm{q})
\end{array} \\
&
\end{aligned}
$$

\footnotetext{
15 This argument follows suggestions by Uli Sauerland (p.c.) and Satoshi Tomioka (p.c.).

${ }^{16}$ Because biir da+N NPIs involve a numeral biir 'one', there is a richer scale than with disjunction, thus exhaustification with $\mathrm{O}(\mathrm{nly})$ is inappropriate. Rather, another exhaustifier E(ven) must be used (see Crnič 2014).
} 
In (22), each alternative starting from $(p \wedge q)$ entails the alternatives in the rows above. That is, $(p \wedge q)$ entails $p,(p \wedge q)$ entails $q$, and $p$ entails $(p \vee q)$, and $q$ entails $(p \vee q)$. There are no entailments in the other direction.

With the notion of alternatives spelled out, we can now exhaustify the alternative of the prejacent $(\mathrm{p} \vee \mathrm{q})$. My claim is that unlike (21), the key difference in Sakha WH+da(qany) is that the alternatives of sentences like (23-a) are marked as obligatorily active (represented by the feature [+ALT]). Following the theory, because the alternatives are obligatorily active, we must exhaustify. Recall from the definition of $\mathrm{O}($ nly) (18) that $\mathrm{O}$ asserts the prejacent and negates all of the alternatives which are not entailed (23-c-ii):

$$
\begin{aligned}
& \text { a. } \text { *Min [kimi da(qany)] kör-d-üm } \\
& \text { 1SG [who.ACC da(qany)] see-PST-1SG } \\
& \text { *'I saw anybody’ } \\
& \text { b. } \llbracket(23-\mathrm{a}) \rrbracket=\exists x[\text { person }(\mathrm{x}) \wedge \mathrm{saw}(\mathrm{I}, \mathrm{x})]_{[+\mathrm{ALT}]} \equiv(\mathrm{p} \vee \mathrm{q})_{[+\mathrm{ALT}]} \\
& \text { c. (i) } \mathrm{ALT}(\mathrm{p} \vee \mathrm{q})=\{\mathrm{p} \vee \mathrm{q}, \mathrm{p}, \mathrm{q}, \mathrm{p} \wedge \mathrm{q}\} \\
& \\
& \text { (ii) Non entailed alternatives of }(\mathrm{p} \vee \mathrm{q})=\{\mathrm{p}, \mathrm{q}, \mathrm{p} \wedge \mathrm{q}\}
\end{aligned}
$$

Exhaustification with $\mathrm{O}($ nly) negates all of the alternatives in (23-c-ii). (24) shows the result of exhaustification, where underbraces indicate logical equivalencies to the above proposition.

$$
\mathrm{O}(\mathrm{p} \vee \mathrm{q})=\underbrace{(\mathrm{p} \vee \mathrm{q}) \wedge \underbrace{\neg \mathrm{p} \wedge \neg \mathrm{q}}_{\neg(\mathrm{p} \vee \mathrm{q})} \wedge \neg(\mathrm{p} \wedge \mathrm{q})}_{(\mathrm{p} \vee \mathrm{q}) \wedge \neg(\mathrm{p} \vee \mathrm{q}) \wedge \neg(\mathrm{p} \wedge \mathrm{q})}
$$

The result of exhaustifying (23-b) with $\mathrm{O}($ nly) results in the LF at the bottom of (24). The key thing to notice here is the string $(p \vee q) \wedge \neg(p \vee q)$. This is a textbook contradiction. The reason that the positive version of (19) does not have a meaning like (21), but rather is an ungrammatical sentence is that da(qany) marks these alternatives as obligatorily active (i.e. grammatically defined). Because they are obligatory, none can be excluded when exhaustifying. If exhaustification contradicts the prejacent, we are left with a contradiction, which cannot be interpretable, hence kim da(qany) being ungrammatical in a positive sentence.

Under negation, no such contradiction will arise. This is because negation scopes over not only the prejacent $(p \vee q)$, but also the alternatives $\{p, q, p \wedge q\}$. The key difference to positive sentences (23) is that negation results in the being entailed.
a. $\quad$ Min [kimi da(qany)] kör-bö-t-üm
1SG [who.ACC da(qany)] see-NEG-PST-1SG
'I didn't see anybody'
b. $\quad \llbracket(25-\mathrm{a}) \rrbracket=\neg \exists \mathrm{x}[\operatorname{person}(\mathrm{x}) \wedge \operatorname{saw}(\mathrm{I}, \mathrm{x})]_{[+\mathrm{ALT}]} \equiv \neg(\mathrm{p} \vee \mathrm{q})_{[+\mathrm{ALT}]}$
c. $\quad$ (i) $\operatorname{ALT}(\neg(\mathrm{p} \vee \mathrm{q}))=\{\neg(\mathrm{p} \vee \mathrm{q}), \neg \mathrm{p}, \neg \mathrm{q}, \neg(\mathrm{p} \wedge \mathrm{q})\}$
(ii) Non-entailed alternatives of $\neg(\mathrm{p} \vee \mathrm{q})=\{\}$

By definition (18) O-exhaustification can only eliminate alternatives which are not entailed by the prejacent. Because, under negation, the alternatives are entailed (25-c-i), there are no non-entailed alternatives to eliminate (25-c-ii). Thus, exhaustification will simply return the prejacent and all of the alternatives:

$$
\mathrm{O}(\neg(\mathrm{p} \vee \mathrm{q}))=\neg(\mathrm{p} \vee \mathrm{q}) \wedge \neg \mathrm{p} \wedge \neg \mathrm{q} \wedge \neg(\mathrm{p} \wedge \mathrm{q})
$$


The lack of contradiction that arises via exhaustification of $\mathrm{WH}+d a($ qany) under negation, then, accounts for its grammaticality in these environments. ${ }^{17}$

3.2. DA(QANY) COORDINATION. As has been variously stated, the main point of tension in an analysis of $d a$ (qany) is that it has the somewhat unexpected property of resulting in univer$\mathrm{sal} /$ conjunction meanings in positive $d a($ qany)...da(qany) coordination (27-a). With negation, it has an existential/disjunction meaning (27-b).

(27) a. Djulus [kof ${ }^{\mathrm{e}}$ da(qany)] [caj da(qany)] is-te

Djulus [coffee da(qany)] [tea da(qany)] drink-PST.3SG

'Djulus drank both coffee and tea'

b. Djulus [kofje da(qany)] [caj da(qany)] is-pe-te

Djulus [coffee da(qany)] [tea da(qany)] drink-NEG-PST.3SG

'Djulus drank neither coffee nor tea'

One approach that has been utilized to explain elements which have a universal/conjunction interpretation in positive environments, but an existential/disjunction interpretation under negation is recursive exhaustification without negating the stronger scalar alternative (see Szabolcsi 2017). ${ }^{18}$ Recursive exhaustification involves exhaustifying not only the alternatives of the prejacent, but also the alternatives of the subdomain alternatives. Assuming that da(qany)...da(qany) coordination in positive environments (27-a) is a disjunction at its core, this approach boils down to proposing that da(qany) marks the alternatives of each disjunct as obligatorily active.

For simplicity, I adopt Chierchia's (2013) $\mathrm{O}_{\text {Exh-DA }}$ operator (28) to represent recursive exhaustifaction as a single operator which distributes $\mathrm{O}($ nly) to the subdomain alternatives of the prejacent (a notion known as "pre-exhaustification".)

(28) $\mathrm{O}_{\text {Exh-DA }}(\mathrm{p} \vee \mathrm{q})$, where $\mathrm{O}_{\text {Exh-DA }}$ says "exhaustify the alternatives of the (sub)domain alternatives with $\mathrm{O}($ nly)"

The alternative set for (27-a) is represented in (29), which consists of two subsets of domain alternatives (29-a)-(29-b).

$$
\operatorname{ALT}(p \vee q)=\{p \vee q, \operatorname{ALT}(p), \operatorname{ALT}(q)\}
$$

a. $\operatorname{ALT}(\mathrm{p})=\{\mathrm{p}, \underline{\mathrm{q}}\}$

b. $\operatorname{ALT}(q)=\{q, \bar{p}\}$

(non-entailed alternatives underlined)

Note in (29-a) and (29-b) that subdomain alternatives are alternatives of each other. We can now see how $\mathrm{O}_{\text {Exh-DA }}$ proceeds:

$$
\begin{aligned}
\mathrm{O}_{\operatorname{Exh}-\mathrm{DA}}(\mathrm{p} \vee \mathrm{q})= & \underbrace{(\mathrm{p} \vee \mathrm{q}) \wedge}_{(\mathrm{p} \vee \mathrm{q}) \wedge(\mathrm{p} \leftrightarrow \mathrm{q})} \underbrace{\underbrace{\neg(\mathrm{p} \wedge \neg \mathrm{q})}_{(\mathrm{p} \rightarrow \mathrm{q})} \underbrace{\neg(\mathrm{q} \wedge \neg \mathrm{p})}_{(\mathrm{q} \rightarrow \mathrm{p})}}_{(\mathrm{p} \leftrightarrow \mathrm{q})}
\end{aligned}
$$

\footnotetext{
17 A note about licensing in comparatives-many analyses (e.g. Gajewski 2008) include a covert degree negation scoping over the comparative. On such an approach, the comparative data in Sakha is a type of licensing via negation.

${ }^{18}$ Recursive exhaustification with the scalar alternative originates in Fox (2007) on free-choice readings of disjunction and has been extended to explain free-choice items by Chierchia (2013).
} 
As shown in top line of (30), $\mathrm{O}_{\text {Exh-DA }}$ applied to the prejacent $(\mathrm{p} \vee \mathrm{q})$ asserts the prejacent and does two more things: first, it applies $\mathrm{O}$ (nly) to each of the subdomain alternatives, and secondly, it negates them (because they are not entailed by $(p \vee q)$. In the logical equivalences beneath, we see that this results in a biconditional $(p \leftrightarrow q)$. On the bottom line, arrive at $(p \vee$ q) $\wedge(p \leftrightarrow q)$, which is logically equivalent to $(p \wedge q)$.

The relevance of not exhaustifying the stronger scalar alternative $(p \wedge q)$ is now quite clear. Because it would directly contradict the sequent $(\mathrm{p} \vee \mathrm{q}) \wedge(\mathrm{p} \leftrightarrow \mathrm{q})$, it would produce an ungrammatical sentence. In $\S 3.3$, I will unify this approach to the explanation of NPIs in $\S 3.1$.

This same approach extends straight-forwardly to the 'neither...nor' reading of $d a(q a n y)$... da(qany) under negation:

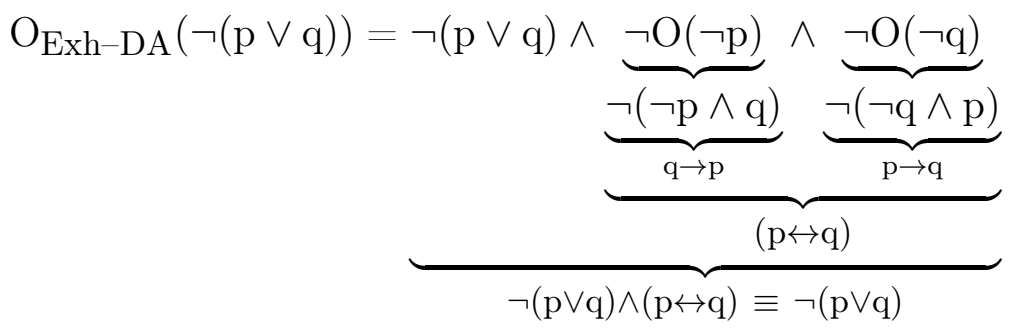

In (31), the result is that the proposition is only true if both of the disjuncts are false. In other words, exhaustification returns the prejacent $\neg(\mathrm{p} \vee \mathrm{q})$.

3.3. TENSION RESOLVED?. In the previous two subsections, an account of the distribution of da(qany)-NPIs and da(qany)...da(qany) coordination was supplied. The main proposal regarding the denotation of $d a$ (qany) is that it has a very simply function: it marks the semantic alternatives of its host as obligatorily active. At the same time, I relied on two related, but distinct, formulations of $\mathrm{O}$ (nly)-exhaustification to arrive at this analysis-non-recursive exhaustification with a stronger scalar alternative $(p \wedge q)$ for the NPIs, and recursive exhaustification without a stronger scalar alternative for the coordination. In both of these cases, the element that $d a$ (qany) is construed with is an existential/disjunction.

This approach accounts for much of the tension that the distribution of da(qany) presents, though there are some additional questions, the biggest being what determines whether a stronger scalar alternative is present or absent? In the works that argue for exhaustification without a stronger scalar alternative, one heuristic is that if a language lacks a distinct lexical item to serve as the alternative for that word, it also lacks that corresponding meaning in the alternative set. This is the line taken by Bowler (2014) in relation to Warlpiri manu 'or, and'-in the language there is no other conjunction than this, so its core disjunction meaning does not contrast with an alternative, hence can be strengthened to and. This cannot be applied to Sakha for two main reasons-firstly, in da(qany) coordination constructions, the particle itself is not properly a conjunction. Rather, as was hinted at in $\$ 2.1 .2$, there is a null conjunction head (following Mitrović \& Sauerland 2014). Secondly, Sakha has a word for 'and': uonna.

The proposal that Sakha da(qany) is essentially a marker to the interpretive part of grammar that the alternatives of the host are active is actually much more conducive to the absence of stronger scalar alternative than it would be to the presence of one. The elements that $d a$ (qany) marks in $d a($ qany)...da(qany) do not necessarily have quantificational force themselves, but are simply sets of alternatives asyndetically joined by a null disjunction. In the case of the NPIs with da(qany), it is the host themselves which have natural scalar alternatives: for 
WH words their scalar alternative is $\forall / \wedge$, for biir 'one' the scalar alternative is the scalar of natural numbers. The addition of da(qany) to the host results in the alternatives being obligatorily active.

So why, then, is there a difference between whether exhaustification applies once (NPIs) or recursively (coordination)? My proposal for this is that it is the very fact that there are two (or more) da(qany)s which forces exhaustification to be recursive. In other words, the doubling is a morphological reflex of recursive exhaustification.

4. Conclusion. This paper has explored the prima facie unexpected fact that Sakha da(ghany) appears in environments that are typically considered existential (i.e. NPIs), but also in coordination with a conjunction 'both...and' meaning. Adopting an exhaustification-based approach to polarity sensitivity, I argued that da(ghany) itself is an element which marks the alternatives of its hosts as obligatorily active. The difference in interpretation is not a property of distinct meanings of the particle, but rather whether exhaustification with $\mathrm{O}$ (nly) applies one (NPIs) or recursively (coordination), as well as whether there is a stronger scalar alternative in the set of alternatives (present in NPIs, lacking in coordination).

\section{References}

Bar-Lev, M. \& D. Margulis. 2014. Hebrew kol: a universal quantifer as an undercover existential. In Urtzi Etxeberria, Anamaria Fălăuş, Artiz Irurtzun \& Bryan Leferman (eds.), Proceedings of Sinn und Bedeutung 18. 60-76.

Böhtlingk, Otto. 1964 [1851]. Über die sprache der jakuten. Indiana University Publications: Uralic and Altaic Series, Vol. 35.

Bowler, Margit. 2014. Conjunction and disjunction in a language without 'and'. Proceedings of Semantics and Linguistic Theory 24. 137-155. https://doi.org/10.3765/salt.v24i0.2422.

Chierchia, Gennaro. 2013. Logic in grammar: Polarity, free choice, and intervention. Oxford: Oxford University Press. https://doi.org/10.1093/acprof:oso/9780199697977.001.0001.

Chierchia, Gennaro, Danny Fox \& Benjamin Spector. 2008. Scalar implicature as a grammatical phenomenon. In Klaus von Heusinger, Claudia Maienborn \& Paul Portner (eds.), Semantics (HSK33.3). 2297-2331. De Gruyter Mouton. https://doi.org/10.1515/9783110253382.

Crnič, Luka. 2014. Non-monotonicity in NPI licensing. Natural Language Semantics 21(2). 169-217. https://doi.org/10.1007/s11050-014-9104-6.

Dayal, Vaneeta. 2016. Questions. New York: Oxford University Press. https://doi.org/10.1093/acprof:oso/9780199281268.001.0001.

Fauconnier, Gilles. 1975. Pragmatic scales and logical structure. Linguistic Inquiry VI(3). 353-375.

Fox, Danny. 2007. Free choice disjunction and the theory of scalar implicatures. In Uli Sauerland \& Penka Stateva (eds.), Presupposition and implicature in compositional semantics. 71-120. Basingstoke: Palgrove Macmillan. https://doi.org/10.1057/9780230210752_4.

Gajewski, Jon. 2008. More on quantifiers in comparative clauses. In Tova Friedman \& Satoshi Ito (eds.), Proceedings of SALT XVIII, Ithaca, NY: Cornell University. https://doi.org/https://doi.org/10.3765/salt.v18i0.2494.

Glinert, Lewis. 1989. The grammar of Modern Hebrew. New York: Cambridge University Press. 
Haspelmath, Martin. 1997. Indefinite pronouns. Clarendon Press. https://doi.org/10.1093/oso/9780198235606.001.0001.

Hoeksema, Jack. 1983. Negative polarity and the comparative. Natural Language and Linguistic Theory 1(3). 403-434. https://doi.org/10.1007/bf00142472.

Kirby, Ian L. 2020. The Sakha particle da(ghany). Manuscript (Harvard University).

Kornfilt, Jaklin. 1997. Turkish. New York: Routledge. https://doi.org/10.4324/9781315823652.

Kratzer, Angelika \& Junko Shimoyama. 2002. Indeterminate pronouns: The view from Japanese. In Yukio Otsu (ed.), The proceedings of the third tokyo conference on pyscholinguistics. Tokyo: Hituzi Syobo.

Ladusaw, William. 1979. Polarity sensitivity as inherent scope relations. University of Texas at Austin dissertation.

Lahiri, Utpal. 1998. Focus and negative polarity in Hindi. Natural Language Semantics 6(1). 57-125. https://doi.org/10.1023/A:1008211808250.

Mitrović, Moreno \& Uli Sauerland. 2014. Decomposing coordination. In Jyoti Iyer \& Leland Kusmer (eds.), Proceedings of NELS 44, vol. 2, 39-52. Amherst, MA: GLSA.

Progovac, Ljiljana. 1994. Negative and positive polarity: A binding approach. New York: Cambridge University Press. https://doi.org/10.1017/cbo9780511554308.

Rooth, Mats. 1985. Association with focus. University of Massachusetts, Amherst dissertation.

Sauerland, Uli. 2004. Scalar implicatures in complex sentences. Linguistics and Philosophy 27(3). 367-391. https://doi.org/10.1023/b:ling.0000023378.71748.db.

Shimoyama, Junko. 2006. Indeterminate phrase quantification in Japanese. Natural Language Semantics 14(2). 139-173. https://doi.org/10.1007/s11050-006-0001-5. Shimoyama,

Junko. 2011. Japanese indeterminate negative polarity items and their scope. Journal of Semantics 28(4). 413-450. https://doi.org/10.1093/jos/ffr004.

Stachowski, Marek \& Astrid Menz. 1998. Yakut. In Lars Johanson \& Éva Ágnes Csató (eds.), The turkic languages, New York: Routledge.

Szabolcsi, Anna. 2010. Quantification. New York: Cambridge University Press. https://doi.org/10.1017/cbo9780511781681.

Szabolcsi, Anna. 2015. What do quantifier particles do? Linguistics and Philosophy 38. 159-204. https://doi.org/10.1007/s10988-015-9166-z.

Szabolcsi, Anna. 2017. Additive presuppositions are derived through activating focus alternatives. In Alexandre Cremers, Thomas van Gessen \& Floris Roelofsen (eds.), Proceedings of the 21st amsterdam colloquium. 455-464. Amsterdam: ILLC.

Szabolcsi, Anna. 2018. Two types of quantifier particles: Quantifier-phrase internal vs. heads on the clausal spine. Glossa 3(1). 1-32. https://doi.org/10.5334/gjgl.538.

Vinokurova, Nadya. 2005. Lexical categories and argument structure: A study with reference to Sakha. Universiteit Utrecht dissertation.

Zwarts, Frans. 1996. Three types of polarity. In F. Hamm \& E. Hinrichs (eds.), Plural quantification. 177-238. Dordrecht: Kluwer. https://doi.org/10.1007/978-94-017-2706-8_5. 